\title{
Armenian and European Methods of Tunnel Waterproofing
}

\author{
Margaryan Aram
}

\begin{abstract}
Waterproofing of underground structures is a complex problem and it requires understanding and thorough analysis in order to successfully achieve the results specified by the designers. The issue is also highly dependent on specifics of the particular project and its details. In the industry that waterproofing the complexity of issue is well known both during the design and construction stages, as well as later during operation and maintenance of the underground facility.This paper is aimed at evaluating and comparing the durability, life expectancy and maintenance needs of the traditional Armenian waterproofing approaches to the overall more rigid waterproofing concepts applied in other European countries.Experiences from operation of newer and older tunnels with different waterproofing approaches were gathered and analyzed.In general, it can be noted that European approach involving double shell draining systems (inner shell of cast concrete with membrane) and single shell undrained systems (waterproof concrete segments) are considered as favorable. Spray applied membranes and waterproof insulating shotcrete are welcomed innovations, but more research is needed to verify their reliability and cost effectiveness compared to the typical solutions applied in European countries.

The methods used to produce waterproof structures range from ground injection and contact grouting to steel linings, watertight concrete and shotcrete and different types of sheet membranes. In the meantime, it is well understood that the industry continues being developed and new and even better products become available and enter the market from time to time, thus only the future will show the actual development in this interesting field.

This article discusses traditional Armenia and European waterproofing concepts in context of finding solutions for future Armenian tunnels. Advantages and challenges with different concepts are highlighted with examples from Armenian and European case projects. Both newer and older tunnels are investigated in order to recognize how the systems perform over time, and in relation to the stated requirements at the time of construction. Concepts for new, innovative waterproofing technology will also be discussed, and the need for further research highlighted.
\end{abstract}

Keywords-Armenian, European, Tunnel Waterproofing, contact grouting, watertight concrete and shotcrete.

\section{INTRODUCTION}

During the last decade numerous investments were made with the purpose to reconstruct and modernize transport infrastructure in Armenia, bringing it to international standards and ensuring speedy and safe commute for traffic,

Margaryan Aram, National University of Architecture and Construction of Armenia. passengers and cargo. Significant number of rehabilitation and reconstruction projects on roads and railways were carried out and are currently being design and implemented, including construction and reconstruction of tunnels. With increasing traffic and reliance on public transport systems, tunnel closures due to essential reconstruction and maintenance may lead to major disruptions and be very expensive. While Germany, as one example, has considered these aspects in the national standards and guidelines for tunnel construction to ensure serviceability for 100 years with low maintenance costs, Armenia still has to review the thresholds and standards considering the differences in approaches applied before and those specifies by international standards and best practice.

One important question for Armenia is whether there is a need to move towards more extensive use of concrete in rock support and waterproofing solutions to be able to achieve the desired service life.The Armenian waterproofing concepts were all developed for conventionally excavated tunnels and developed mostly at Soviet times.As the main part of tunnels are passing through the rocks the most common method of waterproofing is pre-grouting. Its main purpose is to prevent lowering of the groundwater table and to enable a safe construction process. Reduction of seepage in the finished tunnel also has the advantage that it reduces the need for more complex waterproofing solutions. A wide range of rock types and degrees of difficulty are covered. However, it shall also be mentioned, that independent of the pre-grouting scheme and the execution quality, in tunnels where the rock mass is sufficiently permeable, the seepage remains actual problem for tunnel and should be taken into consideration.Hence, in modern high-traffic tunnels a solution to handle the remaining seepage should be implemented

The second place in terms of the frequency of its application in Armenia is waterproofing with a bituminous sheet membrane. With this method almost full waterproofing can be achieved, due to its flexibility and it works great in case of uneven depositions. However, in the meantime this method is very laborious since thesubstrates must be dry, clean and stable before installation commences, surfaces must be smooth and free from nibs, sharp edges, dust, dirt or other materials such as oil, grease or concrete formwork release agents. In addition, it is time consuming sincebased on its technological peculiarities it is hard to mechanize the process.

\section{DISCUSSION}

All these methods of waterproofing are obsolete and have lot of disadvantages so there is a need to introduce modern proofing approaches. Further in the paper the waterproofing approaches applied in Armenia (PE membrane) and European 
countries (Sprayed membrane) are discussed and the advantages and disadvantages of each one are highlighted.

The traditional way of preventing ground water ingress through the tunnel lining is by sheet membrane installed between the primary sprayed concrete support and the permanent in situ concrete lining. Compared to sprayed membrane solutions, the following may be noted:

- Sheet joints must be welded and the quality control must be rigorous to avoid leakage. - Joints in sprayed membrane can be achieved by simply spraying an overlap of $200 \mathrm{~mm}$, Brandenberger et al [1].

- Working with large and heavy sheets that has to be suspended from the roof and walls of the tunnel is labor intensive and time consuming and is hampering other tunnel activities. - Spray application can be executed manually or by robot, allowing easy passage of people and equipment and has little influence on other work activities.

- Undulations in the substrate must be limited to avoid over-stretching the membrane by concrete pressure during final lining concrete pouring. Smoothening shotcrete layer is often required, especially in drill and blast tunneling. In the meantime it shall be emphasized that this is not a concern with sprayed membrane, since it completely follows the substrate undulations.

- The sheet membrane must be protected on the rock side by a geotextile layer to prevent penetration at sharp points. As was also mentioned for the bullet above this is not a concern in case ofsprayed membrane.[3]

- Point damages to the installed membrane can occur during erection of concrete formwork and installation of reinforcement and they may be difficult to detect, even though simple to repair at this stage. Such damage can be prevented by simply applying a thin layer of shotcrete $(30-50 \mathrm{~mm})$ onto the sprayed membrane before start of other works.

- Sprayed concrete will not stick to sheet membranes and can only be applied in combination with geotextile and reinforcement mesh used to tighten up the substrate and provide basis for sprayed concrete build-up. Shotcrete can be applied against sprayed membrane without any special preparations or measures.

- There is no bond between concrete and sheet membrane on either side. This has the effect that pressurized water present on one side of the membrane will 'find' any point damage and cause leakage. Furthermore, the water leaking through the membrane can follow the other side interface and appear visually in construction joints or concrete cracks meters away from the actual leakage point. There is no way to detect the location of the problem and the repair is therefore difficult. In contrast, pressurized water on the rock side will probably not"find" most of the possible damage points in the sprayed membrane, due to the continuous bond. If water still penetrates a weak point, it will not migrate in the membrane/concrete interface. A humid spot or a drip from the cover concrete will therefore show where the damage is and it can be easily sealed by point injection.

- If any kind of penetration of the membrane is required, e.g. for bolts to suspend tunnel installations like ventilation fans, light and cables, signals or reinforcement cages for the final lining, it is difficult to ensure tightness. Sprayed membrane can be applied around such bolts and will seal them off. Bolts can even be drilled for after membrane spraying, provided a simple point injection will be used.

- In a drill and blast excavated hard rock tunnel, frequently the permanent support can be accomplished by an average total shotcrete thickness of less than $250 \mathrm{~mm}$. Permanent in situ concrete linings planned to be about $300 \mathrm{~mm}$ thick, frequently end up being double and triple that, due to overbreak during excavation. If such a lining is there just to keep up a sheet membrane, it becomes a very expensive membrane support. A sprayed membrane can be integrated in a permanent lining shotcrete solution and the thickness of shotcrete need only be as required for support (independent of possible overbreak from blasting).

An important practical point to be aware of is the fact that application of a nonreactive paste, which takes time to dry out (cure), cannot fight active pressurized water through the substrate, at time of application. If such active water is present it will penetrate the membrane before it can set and this will produce a leakage point.

However, contrary to e.g. sprayable systems on polyurethane basis, there is no problem with substrate or air humidity at time of application. Actually, if the substrate concrete is dry, it must be pre-wetted and allowed to surface dry, before application of the membrane. Such surface humidity improves the bond strength and must be ensured before spraying.

The purpose of the thin layer of PE(Polyethylene) membrane in the middle of the sheet is to drain away water migration from the substrate while the spray membrane gets time to dry out.

\section{CONCLUSION}

Based on the analysispresented above the followingconclusion can be made - the waterproofing approaches and methods applied inEuropean countries havein general better functionality and reliability in comparison with the Armenian requirements forrailway and car tunnels and hence areensuring reliable railwayoperation in combination with a long service life.

It is evident from the findings in this study thatthe traditional Armenian waterproofing concept with PEpanels areno longer suited for application. Theonly advantage of this concept excels is itslow investmentcost compared to some of the other solutions.Lightweight concrete segments are also relatively low-costin terms of investment

and have better capabilities withregards to pressure/suction forces and fire safety. However, the need for inspections behind the lining, seepage problems, need for maintenance and the relatively shortservice life are making this option less desirable.

\section{REFERENCES}

[1] Possible Concepts for Waterproofing of Norwegian TBM Railway Tunnels ROCK MECHANICS AND ROCK ENGINEERING · MAY 2014 http://www.researchgate.net/publication/257445534 
Int'I Journal of Research in Chemical, Metallurgical and Civil Engg. (IJRCMCE) Vol. 3, Issue 1 (2016) ISSN 2349-1442 EISSN 2349-1450

[2] COST EFFICIENT WATERPROOF TUNNEL LININGS Knut F. Garshol

Engineering Conferences International Year 2009.

[3] MasterSeal 345 Technical Data Sheet, BASF August 2008 